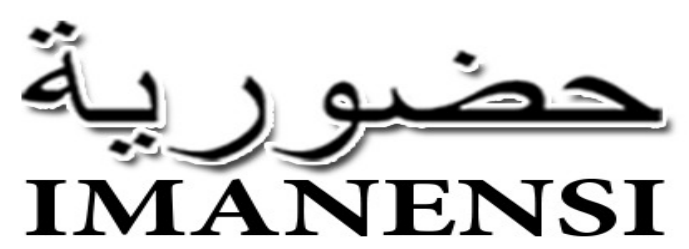

Jurnal Ekonomi, Manajemen, dan Akuntansi Islam

Vol 5, No 2, September 2020, H1mn. 61-68

\title{
Determinan upaya pencegahan fraud pemerintah desa
}

\author{
Irmah Halimah Bachtiara,1,* \\ Ela Elliyana ${ }^{b, 2}$ \\ abUniversitas Indonesia Timur, J1. Rappocini Raya No.171-173, \\ Makassar, 90221, Indonesia. \\ 1irmahalimah@gmail.com*,2 elaelliyana82@gmail.com \\ * correspondence author \\ 10.34202/imanensi.5.2.2020.61-68.
}

\begin{abstract}
Abstrak
Tujuan dilakukan penelitian ini adalah untuk mengukur Internal control, budaya etis organisasi dan karakteristik personal terhadap upaya pencegahan fraud di Kabupaten Bulukumba. Jenis penelitian kuantitatif dimana aparat desa Kabupaten Bulukumba menjadi populasi dan analisis data menggunakan regresi linier berganda. Hasil riset memperlihatkan bahwa pengendalian internal dan budaya etis organisasi memengaruhi pencegahan fraud. Artinya bahwa pengendalian internal dan budaya etis organisasi mampu meningkatkan upaya pencegahan fraud. Namun karakteristik personal bukanlah hal yang bisa memengaruhi tindak kecurangan artinya upaya pencegahan fraud di Kabupaten Bulukumba tidak dipengaruhi oleh umur aparat desa.
\end{abstract}

Kata Kunci: Pengendalian Internal; Budaya Etis Organisasi; Karakteristik Personal.

\begin{abstract}
The purpose of this study was to measure internal control, organizational ethical culture and personal characteristics that influence fraud prevention efforts in Bulukumba Regency. This type of quantitative research, the village apparatus of Bulukumba Regency becomes the population and the data analysis uses multiple linear regression. Research results show that internal control and organizational ethical culture influence fraud prevention, which indicates that both factors can increase fraud prevention efforts. However, personal characteristics are not factors that can influence fraud, meaning that efforts to prevent fraud in Bulukumba Regency are not influenced by the age of village officials.
\end{abstract}

Keywords: Internal Control; Organizational Ethical Culture; Personal Characteristics.
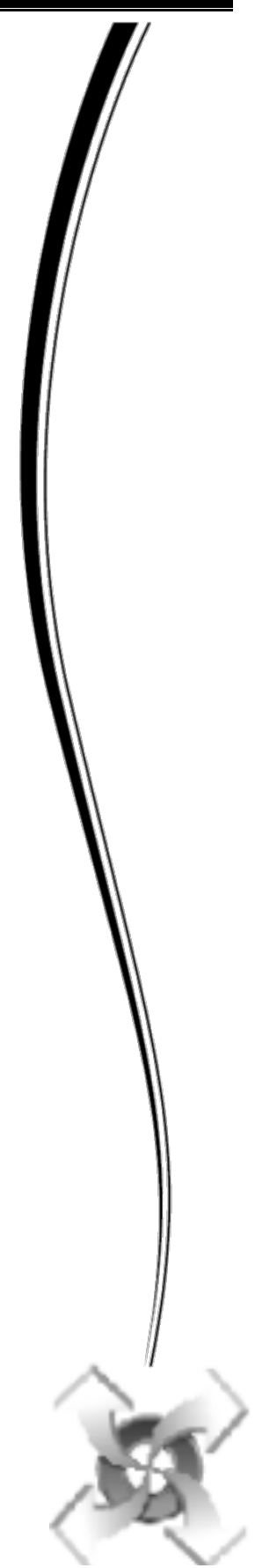

Tanggal Masuk: 1 September 2020 Tanggal Revisi: 16 September 2020 Tanggal diterima: 26 September 2020 


\section{PENDAHULUAN}

Fraud merupakan suatu masalah besar yang harus dituntaskan bagi sektor publik atau pun swasta di Indonesia. Banyaknya kasus yang terjadi menunjukkan bahwa fraud sudah meluas di Indonesia termasuk di lingkungan desa. Pada realisasinya masyarakat sering mengeluhkan proses alokasi anggaran yang tidak sesuai dengan tingkat prioritas kebutuhan dan hanya sedikit mempresentasikan segi aktifitas, efesiensi dan ekonomi (Alfaruqi \& Kristianti, 2019).

Berdasarkan data alokasi dana Desa Tahun 2019 di Daerah Bulukumba sebanyak 109 Desa, jumlah Alokasi Dasar per Desa sebanyak 672.421 jika ditotalkan seluruh alokasi dasar, alokasi afirmasi dan alokasi formula sebanyak 108.344.633 (djpk.kemenkeu, 2019). Jumlah alokasi dana Desa yang terhitung cukup besar sehingga timbulnya potensi disetiap Pemerintah Desa untuk melakukan penyimpangan. Beberapa kasus yang ditemukan, penyalahgunaan dana desa tersebut justru dilakukan oleh aparat desa. Dari hasil penelitian Lembaga Anti Korupsi bahwa terdapat 53 kasus penyalahgunaan dana desa selama periode 2018-2019 yang tersebar di sejumlah kabupaten di Provinsi Sulawesi Selatan. Terdapat 52 orang dari aparat desa yang dijadikan terdakwa dalam kasus korupsi penyalahgunaan Anggaran Dana Desa (ADD), 37 diantaranya sebagai kepala desa dan 15 berasal dari perangkat daerah. Data ICW (Indonesia Corruption Watch) pada tahun 2019 mencatat kasus korupsi di sektor anggaran desa merupakan kasus yang terbanyak ditindaklanjuti oleh aparat penegak hukum apabila dibandingkan dengan beberapa sektor lainnya (Ramadhan, 2020). Dengan melihat beberapa kasus yang ada di Bulukumba, maka penting untuk melakukan pencegahan fraud dana desa pada pemerintah desa.

Salah satu cara yang dapat dilakukan perusahaan untuk mencegah fraud yaitu dengan memiliki sistem pengendalian yang baik (Albrecht, Albrecht, Albrecht, Zimbelman, 2009). Dalam sistem pengendalian Internal juga tidak akan berjalan dengan baik apabila tidak didukung dengan budaya organisasi karena akan menyebabkan perilaku tidak etis sehingga akan mempengaruhi banyaknya penyimpangan pada instansi tersebut. Langkah lain yang dapat ditempuh agar menghindari terjadinya fraud yaitu dengan menciptakan kultur perusahaan yang baik. Kultur perusahaan yang baik bisa tergambar dari budaya etis organisasi. Dari beberapa penelitian menemukan hasil yang berbeda-beda. Dalam penelitian Wijayanti dan Hanafi (2018), kecenderungan fraud dipengaruhi secara positif oleh Sistem pengendalian internal. Sedangkan penelitian Donelson, Ege \& McInnis (2017), Beger, Perreault \& Wainberg (2017) dan Udayani \& Sari (2017) berpengaruh negatif terhadap kecenderungan fraud. Budaya etis organisasi dalam penelitian Donelson, Ege, \& McInnis (2017) ditemukan berpengaruh negatif terhadap kecenderungan fraud tetapi dalam penelitian Najahningrum (2013) tidak berpengaruh, sehingga perlu diteliti kembali mengenai budaya etis. Berdasarkan penelitian Wijayati dan Hanafi (2018) karakteristik usia terbukti kecenderungan fraud dipengaruhi signifikan oleh karakteristik usia.

Penelitian ini mencoba memperbarui penelitian sebelumnya, di mana penelitian sebelumnya menggunakan moralitas individu dan internal control. Pada penelitian ini menggunakan variabel pengendalian internal dan mencoba mengganti variabel moralitas individu dengan budaya etis organisasi. Penelitian ini juga memperbaharui penelitian sebelumnya dengan menambahkan variabel karakteristik personal dengan indikator umur.

Penelitian ini bertujuan untuk: (1) mengetahui pengaruh pengendalian internal terhadap pencegahan tindak kecurangan di Kabupaten Bulukumba, 
(2) mengetahui pengaruh budaya etis terhadap pencegahan fraud di Kabupaten Bulukumba, dan (3) mengetahui bagaimana pencegahan fraud di Kabupaten Bulukumba dipengaruhi oleh karakteristik personal.

\section{METODE}

Riset ini dilakukan melalui survei yang dilaksanakan selama bulan MeiJuli tahun 2020 di Kabupaten Bulukumba, Provinsi Sulawesi Selatan, Indonesia. Asal data yaitu dari hasil angket/kueisoner, yang dialokasikan pada perangkat/aparatur desa yang berjumlah 100 orang dari 20 desa yang mewakili 10 kecamatan di Kabupaten Bulukumba. Populasi dalam penelitian ini adalah aparat desa meliputi kepala desa, sekertaris desa, bendahara desa, dan staf desa yang ada di Kabupaten Bulukumba. Teknik convenience sampling merupakan teknik yang digunakan dalam penentuan sampel penelitian yang berdasarkan kemudahan (Sudaryono, 2018). Teknik analisis data yang dilakukan pada riset ini yakni uji deskriptif statistik menggunakan tes koefisien determinasi, uji $\mathrm{T}$ dan uji $\mathrm{F}$. Kuesioner akan diukur dengan menggunakan skala Likert dengan skor tertinggi di tiap pertanyaannya adalah 5 dan skor terendah adalah 1 . Teknik analisis data menggunakan persamaan regresi linear berganda untuk menguji pengaruh tiap-tiap variabel independen terhadap variabel terikat menggunakan alat analisis statistik SPSS Versi 23. Adapun persamaannya sebagai berikut:

$$
\mathrm{Y}: \boldsymbol{a}+b_{5} x_{3}+b_{2} x_{2}+b_{3} x_{3}+\mathrm{e}
$$

$$
\begin{aligned}
& \text { Keterangan : } \mathrm{Y}=\text { Pencegahan Fraud } \\
& \mathrm{a}=\text { Nilai konstanta } \\
& X_{T}=\text { Variabel } 1 \text { (Sistem pengendalian internal) } \\
& X_{2}=\text { Variabel } 2 \text { (budaya etis organisasi) } \\
& X_{3}=\text { Variabel } 3 \text { (Umur) } \\
& b_{3}=\text { Koefisien regresi variabel bebas } 1 \\
& b_{2}=\text { Koefisien regresi variabel bebas } 2 \\
& b_{3}=\text { Koefisien regresi variabel bebas } 3 \\
& \mathrm{e}=\text { error term }
\end{aligned}
$$

\section{HASIL DAN PEMBAHASAN}

Berdasarkan hasil penelitian dari pembagian kuesioner kepada 100 orang responden yang berasal dari aparat desa yang ada di Kabupaten Bulukumba.

\subsection{Uji Regresi Linear Berganda}

Analisis regresi linear berganda digunakan dalam menguji penelitian ini, dimaksudkan untuk melihat pengaruh variabel independen (pengendalian internal, budaya etis organisasi serta Umur) terhadap variabel dependen (Pencegahan Fraud). Hasil pengujian regresi linear berganda terdapat di Tabel 1. Dari Tabel 1 dapat diketahui bahwa angka konstanta sebesar 9,830, artinya bahwa jika variabel pengendalian internal, budaya etis organisasi, dan Umur dianggap tetap atau konstan maka variabel Pencegahan Fraud sebesar 9,830 dengan persamaan:

$$
Y=9,830+0,392 X_{1}+0,453 X_{2}-0,263 X_{3}
$$


Tabe1 1. Hasil Uji Regresi Linear Berganda Coefficients ${ }^{a}$

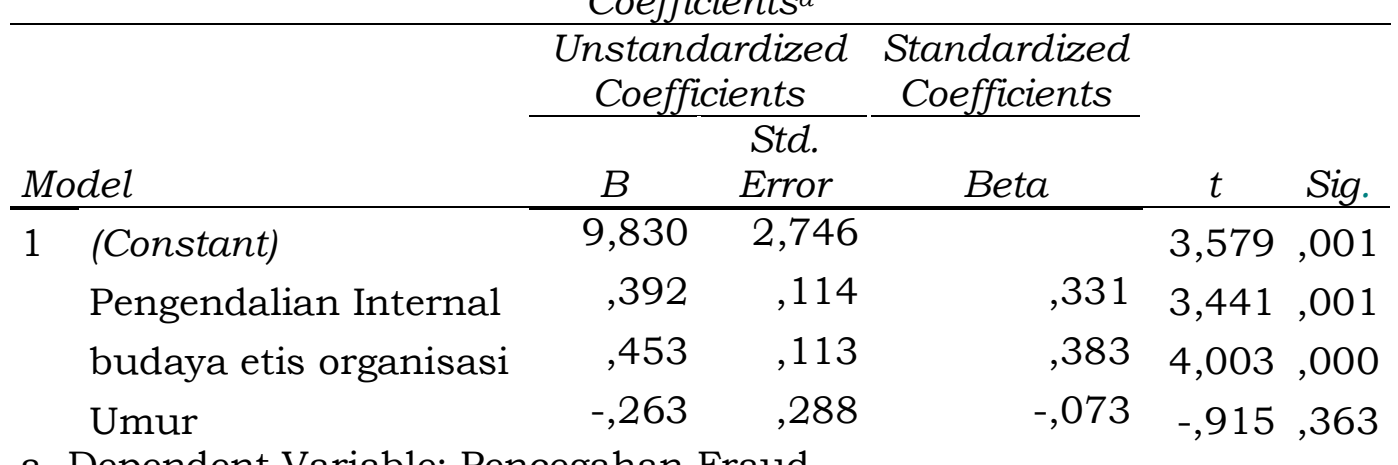

a. Dependent Variable: Pencegahan Fraud

Hasil koefisien regresi menyatakan bahwa variabel pengendalian internal $\left(\mathrm{X}_{1}\right)$ memliki koefisien regresi senilai 0,392 artinya bahwa setiap penambahan pengendalian internal sebesar 1 satuan akan meningkatkan Pencegahan Fraud di Desa yang ada di Kabupaten Bulukumba sebesar 0,392. Pada variabel budaya etis organisasi $\left(\mathrm{X}_{2}\right)$ mempunyai koefisien regresi sebesar 0,453 , yang artinya bahwa penambahan setiap 1 satuan budaya etis organisasi maka akan meningkatkan Pencegahan Fraud di Desa yang ada di Kabupaten Bulukumba sebesar 0,453. Pada variabel Karakteristik Personal $\left(\mathrm{X}_{3}\right)$ yang indikatornya adalah umur mempunyai nilai koefisien sebesar -0,263 artinya bahwa setiap penambahan Umur sebesar 1 satuan maka akan menurunkan Pencegahan Fraud sebesar -0,263. Atau dengan kata lain bahwa jika terjadi penambahan umur aparat desa sebesar 1 satuan maka pencegahan fraud akan berkurang 26,3\% di Kabupaten Bulukumba.

\subsection{Uji Koefisien Determinasi}

Dalam pengujian koefisien determinasi $\left(R^{2}\right)$ berdasarkan ringkasan model (model summary) memperlihatkan jumlah koefisien determinasi yang berguna untuk mengetahui besarnya variabilitas variabel terikat yaitu pencegahan tindak kecurangan yang mampu dijelaskan dengan menggunakan variabel mandiri yaitu pengendalian internal, budaya etis organisasi dan umur.

Tabel 2. Hasil Koefisien Determinasi

\begin{tabular}{|c|c|c|c|c|}
\hline \multicolumn{5}{|c|}{ Model Summaryb } \\
\hline Model & $R$ & $R$ Square & $\begin{array}{c}\text { Adjusted } R \\
\text { Square }\end{array}$ & $\begin{array}{l}\text { Std.Error of } \\
\text { the Estimate }\end{array}$ \\
\hline 1 &, $631 a$ & ,399 & ,380 & 2,38983 \\
\hline
\end{tabular}

Berdasarkan tabel 2 memperlihatkan jumlah adjusted $R$ Square sebanyak 0,380 atau 38\% artinya variabel pengendalian internal, budaya etis organisasi dan umur secara simultan mampu memberikan pengaruh terhadap pencegahan fraud atau tindak kecurangan sebesar 38\% dan sisanya ada variabel lain yang memberikan pengaruh namun tidak masuk dalam penelitian ini.

\subsection{Hasil Uji $t$ dan Uji $F$ (Tes Simultan)}


Uji t dilakukan untuk mendapatkan informasi mengenai model regresi variabel mandiri secara sendiri-sendiri memiliki pengaruh signifikan terhadap dependen atau tidak berpengaruh.

Tabel 3. Ujit

\begin{tabular}{lccc}
\hline Keterangan & t hitung & t table & Sig \\
\hline pengendalian internal & 3,441 & 1,985 & 0,001 \\
Budaya Etis Organisasi & 4,003 & 1,985 & 0,000 \\
Karakteristik Personal (Umur) & $-0,915$ & 1,985 & 0,363 \\
\hline
\end{tabular}

Dari data Tabel 3 dapat diketahui bahwa pengendalian internal dan budaya etis organisasi berpengaruh terhadap Pencegahan Fraud, sedangkan Karakteristik Personal yang diukur dengan Umur tidak berpengaruh terhadap Pencegahan Fraud.

Tabel 4. Hasil Uji F (Uji Simultan)

\begin{tabular}{|c|c|c|c|c|c|c|}
\hline \multicolumn{7}{|c|}{ ANOVA $a$} \\
\hline \multicolumn{2}{|c|}{ Model } & $\begin{array}{c}\text { Sum of } \\
\text { Squares }\end{array}$ & $d f$ & Mean Square & $F$ & Sig. \\
\hline 1 & Regression & 363,475 & 3 & 121,158 & 21,214 & ,000b \\
\hline & Residual & 548,285 & 96 & 5,711 & & \\
\hline & Total & 911,760 & 99 & & & \\
\hline
\end{tabular}

a. Dependent Variable: Pencegahan Fraud

b. Predictors: (Constant), pengendalian internal, budaya etis organisasi, Umur

Tabel 4 menunjukkan bahwa, uji ANOVA menghasilkan angka $F$ sebesar 21,214 pada taraf signifikansi yaitu 0,000. Karena angka probabilitas < 0,05 ( $0,000<0,05)$, maka persamaan regresi tersebut bisa digunakan dalam mengestimasi pencegahan fraud. Dengan kata lain, variabel-variabel independen (pengendalian internal, budaya etis organisasi dan Umur bersama-sama memiliki pengaruh signifikan terhadap variabel dependen (Pencegahan Fraud).

\subsection{Pengaruh Internal Control Terhadap Pencegahan Kecurangan}

Dari hasil penelitian diperoleh hasil bahwa meminimalkan kecurangan dipengaruhi secara signifikan oleh variabel pengendalian internal, di mana dapat dilihat dari tingkat signifikansi $0,001<0,05$ dengan taraf signifikan 0,05 dan $t_{\text {hitung }}$ bernilai 3,441 dan $t_{\text {tabel }}(3,441>1,985)$ sehingga pengendalian internal berpengaruh signifikan terhadap Pencegahan Fraud. Hasil ini memperkuat hasil penelitian terdahulu telah dilaksanakan oleh Barra (2010) dan Doig (2014), setelah dilakukan pengujian diperoleh hasil yang menunjukkan bahwa pengendalian internal berpengaruh positif dan relevan pada kecenderungan fraud.

Hasil penelitian ini menunjukkan bahwa sistem pengendalian internal yang diterapkan oleh aparat desa yang ada di Kabupaten Bulukumba mampu meningkatkan upaya dalam pencegahan fraud. Hal ini terlihat dari struktur organisasi yang jelas, penentuan batas serta standar etika yang diterapkan mampu mengatur aparat desa dalam bersikap dan berperilaku dalam bekerja, serta adanya pengenaan sanksi bagi aparat desa yang melanggar. Selain itu, informasi mengenai dana desa disajikan dalam bentuk laporan keuangan. 
Dari segi Aktifitas pengendaliannya, sudah terstruktur cukup baik, setiap transaksi atau kegiatan beserta dokumennya sudah jelas penanggung jawabnya masing-masing. Pemeriksaan dan pengawasan secara rutin terhadap prosedur dan kebijakan pemerintah desa telah dilakukan dengan baik untuk dapat meminimalisir kecurangan yang terjadi. Peningkatan pengendalian internal dalam upaya pengelolaan keuangan desa secara efektif mampu mengurangi terjadinya fraud yang ada di Kabupaten Bulukumba.

\subsection{Pengaruh Budaya Etis Organisasi Terhadap Pencegahan Fraud}

Dampak budaya etis organisasi terhadap pencegahan fraud memiliki angka signifikansi $0,000<0,05$ dengan taraf signifikansi 0,05, dan thitung sebesar 4,003. Nilai ini jika dibandingkan dengan tabel sebesar 1,985 maka $t_{\text {hitung }}$ masih jauh dibandingkan $t_{\text {tabel }}(4,003>1,985)$ sehingga budaya etis organisasi berpengaruh signifikan terhadap Pencegahan Fraud. Hasil penelitian ini bertentangan dari hasil penelitian Najahningrum (2013) yang mana ditemukan Fraud tidak dipengaruhi oleh budaya etis organisasi serta penelitian Donelson, Ege, \& McInnis (2017) di mana hasil pengujian mereka ditemukan yakni kecenderungan fraud dipengaruhi secara negatif oleh budaya etis organisasi. Namun hasil ini searah dengan penelitian yang dilakukan Widiyarta et al (2017) yaitu hasil pengujian menemukan bahwa Pencegahan Fraud dipengaruhi secara positif dan signifikan oleh budaya etis organisasi. Hal ini berarti bahwa semakin tinggi budaya etis organisasi maka akan berdampak pada meningkatnya pencegahan fraud dalam pengelolaan keuangan desa di Kabupaten Bulukumba.

Hasil penelitian menunjukkan bahwa para aparat pemerintahan desa sudah bertanggung jawab menurut aturan dan kode etik yang telah ditetapkan,. Selain itu, terjalin komunikasi yang baik antar pegawai maupun dengan pimpinan. Kepala desa selaku pimpinan mampu membina serta meningkatkan semangat kerja anggotanya, melalui kegiatan sosialisasi serta penataran tentang standar organisasi yang sinkron dengan prosedur dan tidak melanggar kode etik. Hasil penelitian ini tentunya mendukung teori yang dikemukakan Arens et al (2008) bahwa Kejujuran dan beretika adalah salah satu aspek yang mampu mencegah kecurangan. Tata kelola Pemerintahan desa yang baik dipercaya mampu mengelola keuangan desa secara tepat dan akurat dan mampu meminimalkan risiko terjadinya fraud di Kabupaten Bulukumba

\subsection{Pengaruh Karakteristik Personal Terhadap Pencegahan Fraud}

Berdasarkan hasil penelitian menunjukkan bahwa variabel karakteristik personal yang diukur dengan menggunakan umur di mana nilai signifikansi 0,363 > 0,05 dan mempunyai thitung yaitu $-0,915<$ nilai $t_{\text {tabel }} 1,985$, maka dapat disimpulkan bahwa variabel karakteristik personal tidak berpengaruh terhadap pencegahan fraud. Hasil penelitian ini menunjukkan bahwa umur seseorang belum mampu dijadikan tolak ukur dalam pencegahan fraud.

Fraud yang terjadi bisa dilakukan oleh siapa saja tanpa memandang umur. Seseorang yang memiliki umur yang masih tergolong muda maupun tua tidak mampu dijadikan acuan dalam melakukan pencegahan fraud. Manusia terkadang melakukan kecurangan karena adanya keserakahan dan kebutuhan manusia yang tak terbatas baik itu untuk aparat yang masih muda maupun yang sudah tua. Hal ini mendukung teori GONE, di mana seseorang akan melakukan kecurangan karena keserakahan dan kebutuhan bersifat personal yaitu berkaitan dengan prilaku individu ataupun kelompok organisasi yang tidak memandang umur. Dalam penelitian ini, umur tidak 
berpengaruh relevan pada upaya mencegah tindak kecurangan karena fraud tidak hanya dipengaruhi oleh variabel karakteristik personal, melainkan juga ada banyak faktor lain seperti moralitas individu dan kompetensi aparatur. Hasil ini searah dengan hasil temuan yang dilakukan oleh Wijayanti dan Hanafi (2018).

\section{SIMPULAN}

Upaya pencegahan fraud di Kabupaten Bulukumba dipengaruhi pengendalian internal dan budaya etis organisasi, sedangkan karakteristik personal yaitu umur aparat desa tidak berpengaruh terhadap pencegahan fraud di Kabupaten Bulukumba. Saran penelitian, yaitu: pertama, bagi pemerintah desa yang terdiri dari aparat desa (kades, sekdes, bendahara, kepala bagian maupun staf desa) Kabupaten Bulukumba diharapkan perlu meningkatkan budaya etis organisasi sebagai upaya pencegahan fraud, mengingat hasil penelitian ini menunjukkan variabel budaya etis organisasi memiliki nilai signifikansi tertinggi dari pada variabel lainnya. Kedua, untuk peneliti selanjutnya agar menambah variabel lain dari pengukuran karakteristik personal selain umur misalnya gender, tingkat pendidikan atau faktor lain yang mungkin berpengaruh terhadap pencegahan fraud.

\section{UCAPAN TERIMA KASIH}

Ucapan terima kasih kepada Pihak DRPM Kemenristek/Brin yang telah memberikan Hibah dana penelitian, Ketua LPPM dan teman-teman Dosen Universitas Indonesia Timur Makassar yang telah banyak membantu dalam pelaksanaan PDP ini, serta semua pihak Aparat Desa yang ada di Kabupaten Bulukumba yang sudah berpartisipasi dalam pelaksanaan penelitian ini.

\section{REFERENSI}

Albrecht, S.,Albrecht, C., Albrecht, C.,Zimbelman, M.(2009). Fraud Examination, 3rd ed., South-Western Cengange Learning, Mason.

Artini, NLEA, I Made Pradana Adiputra, N. T. H. (2013). Pengaruh Budaya Etis Organisasi Dan Efektivitas Pengendalian Internal Terhadap Kecenderungan Kecurangan Akuntansi Pada Satuan Kerja Perangkat Daerah (Skpd) Kabupaten Jembrana. JIMAT (Jurnal Ilmiah Mahasiswa Akuntansi S1), 2(1). https://doi.org/10.23887/jimat.v2i1.2884.

Alfaruqi, I., \& Kristianti, I. (2019). Analisis Potensi Kecurangan Dalam Pengelolaan Keuangan Desa (Studi: Desa Kesongo, Kecamatan Tuntang, Kabupaten Semarang, Jawa Tengah). Jurnal Akuntansi Maranatha, 11(2), 199-210. https://doi.org/10.28932/jam.v11i2.1915

Arens, Alvins A., Elder, dan Beasley. (2008). Auditing dan Jasa Assurance Pendekatan Terintegrasi Jilid 1. Edisi 12. Jakarta: Erlangga.

Babulu, N. L. (2020). Faktor-Faktor Yang Mempengaruhi Akuntabilitas Dalam Pengelolaan Dana Desa dan Dampaknya Terhadap Pencegahan Fraud. Ekopem: Jurnal Ekonomi Pembangunan, 5(2), 18-26. https://doi.org/10.32938/JEP.V5I2.594.

Barra, Roberta Ann (2010). The Impact of Internal Controls and Penalties on Fraud. Journal of information system: Spring 2010, Vol.24, No. 1, p. 1-21.

Berger, L., Perreault, S., \& Wainberg, J. (2017). Hijacking the Moral Imperative: How Financial Incentives Can Discourage Whistleblower Reporting. Auditing: A Journal of Practice \& Theory, 36(3), 1-14.

DJPK.KEMENKEU. (2019). Rincian Dana Desa Menurut Kabupaten/Kota T.A. 2019. Diakses tanggal 29 Agustus 2020 dari 
http://www.djpk.kemenkeu.go.id/wp-content/uploads/2018/10/DANADESA-1.pdf.

Doig, A. (2014). Readworks Ahead? Addressing Fraud, Corruption and Conflict of Interest in English Local Goverments. Local Government Studies, 40 (5), 670-686.

Donelson, D. C., Ege, M. S., \& McInnis, J. M. (2017). Internal Control Weaknesses and Financial Reporting Fraud. Auditing: A Journal of Practice \& Theory, 36(3), 45-69

Fadilah, N. (2018). Pengaruh Karakteristik Personal, Internal Control dan Ketaatan Aturan Akuntansi Terhadap Kecenderungan Kecurangan Akuntansi dengan Perilaku Etis Sebagai Variabel Moderating. NASPA Journal. https://doi.org/10.1017/CBO9781107415324.004

Isgiyata, J., Indayani, I., \& Budiyoni, E. (2018). Studi Tentang Teori GONE dan Pengaruhnya Terhadap Fraud Dengan Idealisme Pimpinan Sebagai Variabel Moderasi: Studi Pada Pengadaan Barang/Jasa di Pemerintahan. Jurnal Dinamika Akuntansi Dan Bisnis, 5(1), 31-42. https://doi.org/10.24815/jdab.v5i1.8253

Ramadhan, Ardito. (2020, Juli-18). Catatan ICW, Kasus Korupsi Dana Dena Terbanyak Muncul 2019. Kompas.com. Diakses pada 27 Juli 2020 dari https://nasional.kompas.com/read/2020/02/18/19084421/catatan-icwkasus-korupsi-dana-desa-terbanyak-muncul-pada-2019.

Najahningrum, Anik Fatun. (2013). Faktor-Faktor Yang Mempengaruhi Kecenderungan Kecurangan (Fraud): Persepsi Pegawai Dinas Provinsi DIY. Under Graduates thesis, Universitas Negeri Semarang.

Artini, NLEA, I Made Pradana Adiputra, N. T. H. (2013). Pengaruh Budaya Etis Organisasi Dan Efektivitas Pengendalian Internal Terhadap Kecenderungan Kecurangan Akuntansi Pada Satuan Kerja Perangkat Daerah (Skpd) Kabupaten Jembrana. JIMAT (Jurnal Ilmiah Mahasiswa Akuntansi S1), 2(1). https://doi.org/10.23887/jimat.v2i1.2884.

Rahimah, Laila Nur, dkk. (2018). Pengaruh Penyajian Laporan Keuangan Desa, Lingkungan Pengendalian dan Moralitas Individu Terhadap Pencegahan Fraud Yang Terjadi Dalam Pengelolaan Alokasi Dana Desa. Jurnal Ilmiah Ilmu Ekonomi. Volume 6 Edisi 12.

Saputra, K. A. K., Pradnyanitasari, P. D., Priliandani, N. M. I., \& Putra, I. G. B. N. P. (2019). Praktek Akuntabilitas Dan Kompetensi Sumber Daya Manusia Untuk Pencegahan Fraud Dalam Pengelolaan Dana Desa. Krisna: Kumpulan Riset Akuntansi, 10(2), 168-176.

Sudaryono. (2018). Metodologi Penelitian. Ed. 1 Cet.2. Depok: Rajawali Pers.

Udayani, Anak Agung K.F dan Maria M. Ratna Sari. (2017). Pengaruh Pengendalian Internal dan Moralitas Individu pada Kecenderungan Kecurangan Akuntansi. E-Jurnal Akuntansi Universitas Udayana. Volume 18 No.3 (Maret).

Widiyarta, Kadek., Nyoman T.H., \& Anantawikrama T. A. (2017). Pengaruh Kompetensi Aparatur, Budaya Organisasi, Whistleblowing dan Sistem Pengendalian Internal Terhadap Pencegahan Fraud Dalam Pengelolaan Dana Desa. Jurnal Imiah Mahasiswa. Volume 8, Nomor 2.

Wijayanti, P., \& Hanafi, R. (2018). Pencegahan fraud Pada pemerintahan desa. Jurnal Akuntansi Multiparadigma, 9(2), 331-345. 